\title{
Research on Green Total Factor Productivity of Logistics Industry and its threshold effect of Environmental Regulation
}

\author{
Li Wanchun ${ }^{1}$ \\ ${ }^{1} \mathrm{Xi}$ an Siyuan University, Shaanxi, China
}

\begin{abstract}
This paper is based on the input-output panel data of logistics industry in 30 provinces and regions in China from 2005 to 2017, using nonparametric DEA model to evaluate the green total factor productivity of logistics industry, and build a panel threshold model to empirically test the nonlinear impact of environmental egulation. It is found that environmental regulation has a double threshold effect on green total factor productivity of logistics industry, the estimated threshold values are 89.85 and 211.27 respectively; when environmental regulation is at a low level below 89.85 , environmental regulation has a positive effect of $2.09 \%$ on green total factor productivity of logistics industry, when environmental regulation is in the intermediate stage of 89.85 to 211.27 , environmental regulation has a positive improvement effect of $6.41 \%$ on green total factor productivity of logistics industry; when environmental regulation is at a higher level than 211.27 , environmental regulation has a negative inhibitory effect of $1.57 \%$ on green total factor productivity of logistics industry. Based on the empirical conclusion, this paper puts forward: First, using the performance assessment as the baton to urge the local government to establish an effective environmental regulation system; second, the government should plan to guide the green transformation and upgrading of the logistics industry to avoid "one size fits all" environmental regulation.
\end{abstract}

\section{Introduction}

According to the 2017 (GCP) report on the work of Global carbon projects, the dependence of China's rapidly developing economy on the elements of non-renewable resources has been high, the central government has made a commitment to save energy and reduce emissions at the World Climate Summit, the carbon dioxide emission per unit of GDP in China is $40 \%$ lower than the promised level in 2020 and $45 \%$ lower than that in 2005, and bring the relevant environmental regulation into the medium-and long-term planning of national economic and social development[1]. Logistics industry is an important component of China's tertiary industry and an "accelerator" of national economic development. According to the data of the National Bureau of Statistics, the total income of logistics industry in 2017 is 8.8 trillion yuan, $11.5 \%$ yearon-year growth; logistics of industrial products totaled 234.5 trillion yuan, an increase of $6.6 \%$ over the same period last year; the total cost of social logistics was 12.1 trillion yuan, an increase of $9.2 \%$ over the same period last year. The rapid development of logistics industry has also brought about high energy consumption and high carbon pollution emissions, the proportion of logistics carbon emissions in China's total emissions increased from $4.21 \%$ in 2005 to $9.26 \%$ in 2017[2], it can be seen that the energy saving and emission reduction of the logistics industry has become the key implementation object of China's environmental regulation policy. Therefore, under the dual background of the construction of ecological civilization and the sustainable development of logistics industry, the study of green total factor productivity of logistics industry will help to promote the development of logistics industry from input growth to efficiency growth in the construction of ecological civilization economic society.

Summarizing the literature on the relationship between the development of logistics industry and environmental regulation at home and abroad, we can see that the research focuses on carbon emission evaluation and carbon emission improvement of logistics industry. First of all, this paper uses the non-parametric data envelopment method to measure the green total factor productivity of the logistics industry, and further tests the non-linear relationship between environmental regulation and green total factor productivity through the double threshold model. To provide useful enlightenment for energy saving and emission reduction of logistics industry.

\section{Evaluation of Green Total Factor Productivity of Logistics Industry}

\subsection{Construction of nonparametric DEA model and selection of input-output indicators}

Based on the theory of total factor productivity put forward by Solow, the promoting role of green total factor productivity of logistics industry in the black box of economic system is to exclude the output of other factors 
such as capital and labor. The calculation method can be realized by constructing the input-output non-parametric production frontier of the logistics economic system[3]. The non-parametric DEA model can be solved by linear programming according to the choice of scale reward of economic output in the measurement of total factor productivity. Based on this, this paper constructs DEA model to measure the efficiency of logistics industry. Under the assumption that the scale return is constant, the sample efficiency is expressed as follows:

$$
\begin{aligned}
& \min _{\theta, \lambda} \theta, \\
& \text { s.t. } \quad-\mathbf{y}_{\mathbf{i}}+\sum_{\substack{j=1 \\
j \neq i}}^{n} \lambda_{j} \mathbf{y}_{\mathbf{j}} \geq \mathbf{0} ; \\
& \theta \mathbf{x}_{\mathbf{i}}-\sum_{\substack{j=1 \\
j \neq i}}^{n} \lambda_{j} \mathbf{x}_{\mathbf{j}} \geq \mathbf{0}, \boldsymbol{\lambda} \geq \mathbf{0}
\end{aligned}
$$

Model (1) the expression reference set, projection point and decision making unit are described, and the Malmquist index calculated based on this model is the efficiency value. The definition of efficiency according to the input-output decision-making unit of the logistics industry is as follows:

$D_{t}(x, y)=\inf \{\theta:(x, y / \theta)\} \in P(x) \quad \mathrm{P}(\mathrm{x})$ is the possible convex set of the system output of the logistics industry, and $\theta$ is the efficiency of input and output. $\mathrm{X}, \mathrm{y}$ and $\mathrm{E}$ represent the input factors of the logistics industry. The output efficiency of the logistics industry is expressed by the degree of change of the decomposed decision-making unit. When the efficiency is positive, it indicates the relative efficiency between the input factors of the logistics industry and the best production frontier, and vice versa.

This paper selects the fixed assets investment, the number of employees at the end of the year and the transport efficiency of the logistics industry as the main indicators, in which the transport efficiency includes four aspects: aviation, highway, waterway and railway. the calculation method is obtained by dividing the total amount of freight of different modes of transport by the length of the route of the mode of transport[4].

This paper draws lessons from the algorithm of Chen Shiyi (2011) and others, and calculates the reference coefficient provided by the IPCC2006 carbon emission calculation guide. the specific formula is as follows:

$$
c o_{2}=\sum_{i=1}^{7} c o_{2 i}=\sum_{i=1}^{7} E \cdot N C V_{i} \cdot C E F_{i} \cdot C O F_{i} \cdot 44 / 12
$$

Among them, ${ }^{E_{i}}$ represents the consumption of seven kinds of energy, such as raw coal, gasoline, kerosene, diesel, fuel oil, liquefied petroleum gas and natural gas; $\mathrm{NCV}_{i} 、 C E F_{i}$ and $\mathrm{COF}_{i}$ represent the average low calorific value, carbon emission reference coefficient and carbon oxidation factor of the above energy, respectively.

\subsection{Evaluation results of Green Total Factor Productivity in Logistics Industry}

Based on the input-output index of logistics industry, this paper uses the BCC model in DEAP2.1 software to calculate the green total factor productivity of logistics industry. After data Envelopment Analysis (DEA), we can get the evaluation results of 30 provinces and regions (except Tibet) (limited by space, only part of the year results are listed), as shown in Table 1.

\begin{tabular}{|c|c|c|c|c|c|c|c|c|c|c|c|c|c|c|c|}
\hline area & 2005 & 2007 & 2009 & 2011 & 2013 & 2015 & 2017 & area & 2005 & 2007 & 2009 & 2011 & 2013 & 2015 & 2017 \\
\hline Bejing & 1.00 & 1.00 & 0.82 & 0.90 & 0.86 & 0.94 & 0.99 & Henan & 0.73 & 0.88 & 0.86 & 0.83 & 0.86 & 0.88 & 0.83 \\
\hline Tianjin & 1.00 & 1.00 & 1.00 & 1.00 & 1.00 & 0.93 & 0.92 & Hubei & 0.65 & 0.64 & 0.63 & 0.61 & 0.60 & 0.59 & 0.58 \\
\hline Hebei & 1.00 & 1.00 & 0.72 & 1.00 & 1.00 & 0.90 & 0.93 & Hunan & 0.89 & 0.86 & 0.72 & 0.79 & 0.76 & 0.73 & 0.80 \\
\hline Shanxi & 1.00 & 1.00 & 0.88 & 0.90 & 0.95 & 0.98 & 1.00 & Guangdong & 1.00 & 1.00 & 1.00 & 0.82 & 0.80 & 0.78 & 0.77 \\
\hline Neinnnggu & 0.88 & 0.86 & 0.85 & 0.73 & 0.81 & 0.80 & 0.78 & Guangri & 0.71 & 0.70 & 0.68 & 0.67 & 0.66 & 0.64 & 0.63 \\
\hline Liawaing & 0.89 & 0.98 & 0.86 & 0.84 & 0.82 & 0.81 & 0.79 & Hainan & 0.74 & 0.73 & 0.71 & 0.70 & 0.68 & 0.67 & 0.66 \\
\hline Jjin & 0.63 & 0.63 & 0.62 & 0.61 & 0.60 & 0.59 & 0.58 & Chongging & 0.76 & 0.74 & 0.73 & 0.71 & 0.70 & 0.68 & 0.67 \\
\hline $\begin{array}{l}\text { Heilongian } \\
\mathrm{g}\end{array}$ & 0.66 & 0.54 & 0.44 & 0.46 & 0.70 & 0.54 & 0.70 & Sichuan & 0.82 & 0.80 & 0.79 & 0.77 & 0.76 & 0.74 & 0.73 \\
\hline Shanghai & 1.00 & 1.00 & 1.00 & 1.00 & 1.00 & 0.94 & 0.99 & Guithou & 0.60 & 0.59 & 0.58 & 0.57 & 0.56 & 0.54 & 0.53 \\
\hline Jiangy & 1.00 & 0.93 & 0.85 & 0.87 & 0.90 & 1.00 & 0.93 & Yunnan & 0.62 & 0.61 & 0.60 & 0.59 & 0.58 & 0.56 & 0.55 \\
\hline Zhejang & 0.95 & 1.00 & 0.85 & 0.84 & 0.82 & 0.80 & 0.79 & Shanx & 0.66 & 0.65 & 0.63 & 0.62 & 0.61 & 0.60 & 0.58 \\
\hline Antuix & 0.83 & 0.85 & 0.87 & 1.00 & 1.00 & 0.93 & 1.00 & Gansy & 0.69 & 0.68 & 0.67 & 0.65 & 0.64 & 0.63 & 0.61 \\
\hline Fujian & 0.91 & 0.89 & 0.74 & 0.81 & 0.77 & 0.74 & 0.81 & Qinghaj & 0.60 & 0.59 & 0.58 & 0.57 & 0.56 & 0.54 & 0.53 \\
\hline Jiangi & 0.83 & 0.84 & 0.70 & 0.79 & 0.90 & 0.82 & 0.92 & Ningxia & 0.51 & 0.50 & 0.49 & 0.48 & 0.47 & 0.46 & 0.45 \\
\hline Shandong & 0.89 & 1.00 & 0.98 & 0.99 & 0.87 & 0.98 & 0.99 & Xipijiang & 0.51 & 0.50 & 0.49 & 0.48 & 0.47 & 0.46 & 0.45 \\
\hline
\end{tabular}

Table1. Evaluation results of Green Total Factor Productivity of Logistics Industry in China and provinces and regions (2005-2017)

The evaluation results in Table 1 can be seen as follows:

- The average green total factor productivity of logistics industry in Beijing, Shanghai, Shandong, Jiangsu, Tianjin, Hebei and Anhui provinces all exceeded the national evaluation level in the sample year, and the three regions of Shanghai, Hebei and Tianjin maintained the green total factor productivity of logistics industry as 1 in most years. Shandong, Beijing and Jiangsu provinces have also reached the technical efficiency state of green total factor productivity of logistics industry in some years.

- The green total factor productivity of logistics industry in Zhejiang, Shanxi, Henan, Inner Mongolia, Ningxia, Liaoning and Fujian is higher than the national average in most years, and only in some years is lower than the national average. Among them, the efficiency of Liaoning and Zhejiang is relatively stable, and there is a trend of continuous improvement in Henan, Fujian and Shanxi.

- The green total factor productivity of logistics industry in Chongqing, Guangdong, Jiangxi, Heilongjiang, Sichuan and Hunan provinces is lower than the national average in most years. Only in some years, the efficiency measurement is effective (Guangdong Province is the first frontier of efficiency in 2005 and 2007-2009). The green total factor productivity of logistics industry in Heilongjiang and Hunan has a declining trend.

- The green total factor productivity of logistics industry in Xinjiang, Jilin, Guizhou and other ten provinces is low, and the efficiency evaluation value is lower than the national average during the sample period, which belongs to the state of inefficiency. 


\section{Non-linear effect of Environmental Regulation on Green Total Factor Productivity of Logistics Industry}

\subsection{Model construction and index description}

The panel threshold model can more significantly observe the characteristics of outliers in panel data in testing the nonlinear relationship of variables, and eliminate the abnormal interference of maximum and minimum values[5]. Based on the non-linear and multiple equilibrium characteristics that may exist in the impact of environmental regulation on the green total factor productivity of logistics industry, this paper tests the observed values of logistics industry efficiency variables in the panel threshold model in groups. Regression analysis was carried out according to the values of different threshold variables, and the characteristics of homogeneity or heterogeneity within groups were studied. The representation of the built single threshold panel model is as follows:

$Y_{i t}=\alpha K_{i t}+\beta L_{i t}+\theta_{1} \times G_{i t} \times T\left(q_{i t}<\tau\right)+\theta_{2} \times G_{i t} \times T\left(q_{i t} \geq \tau\right)+\mu_{i}+\varepsilon_{i t}$

Among them, $\mathrm{i}$ is the time section, $\mathrm{t}$ is the regional section, $Y_{i i}$ is the efficiency output of the logistics industry, $L_{i}$ is the labor input factor, $K_{i i}$ is the capital input factor, $G_{i t}$ is the physical quantity factor growth rate. According to the threshold model framework, the parallel indexes of technical efficiency growth $\left(E_{i t}\right)$ and technological progress growth $\left(P_{i t}\right)$ in the cross-section area are further grouped into $\mathrm{E}$ and $\mathrm{P}$, in which the unknown threshold value is expressed by $\tau$ and the scalar is expressed by $q_{i t}$. The individual effect is expressed by $\mu_{i}$, the random disturbance term is expressed by $\varepsilon_{i t}$, and the index function is $T(\bullet)$. According to the constructed panel threshold model, the double threshold frames of $\tau_{1}$ and $\tau_{2}$ $\left(\tau_{1}<\tau_{2}\right)$ are further set for the single threshold.

$Y_{i t}=\alpha K_{i t}+\beta L_{i t}+\theta_{1} \times G_{i t} \times T\left(q_{i t}<\tau_{1}\right)+\theta_{2} \times G_{i t} \times T\left(\tau_{1} \leq q_{i t}<\tau_{2}\right)+\theta_{3} \times G_{i t} \times T\left(q_{i t} \geq \tau_{2}\right)+\mu_{i t}+\varepsilon_{i t}$

\subsection{Double threshold test and analysis}

In the threshold model of environmental regulation affecting green total factor productivity of logistics industry, which is constructed in this paper. It was originally assumed that there is no threshold effect in the nonlinear effect of environmental regulation. The alternative hypothesis is that there is a single threshold effect of environmental regulation on green total factor productivity in logistics industry. Statistics $\mathrm{F}=\left(\mathrm{S}_{0}-\mathrm{S}_{1}(\hat{\tau})\right) / \hat{\sigma}^{2}$ constructed in the model, in which $\mathrm{S}_{i}$ indicates that there is no or only a single threshold effect of residual square sum of environmental regulation and green total factor productivity of logistics industry, and $\hat{\sigma}^{2}$ is the residual variance of variables. On the basis of a single threshold, the second kind of threshold is further searched according to the F statistics, and the double threshold is modified under the condition that the first threshold is fixed and the corresponding sum of squares of the residual is determined. The critical value of $F$ statistics comes from the results of bootstrap method proposed by
Hansen (1999). The test results of the threshold effect are shown in Table 2.

Table2. threshold effect test data table

\begin{tabular}{|l|c|c|c|c|c|}
\hline $\begin{array}{l}\text { Model form } \\
\text { value }\end{array}$ & s statistics & $p$ value & $1 \%$ critical & $\begin{array}{l}\text { value } \\
\text { critical }\end{array}$ & value 10\% critical \\
\hline Single threshold & 87.72 & 0.01 & 48.42 & 33.20 & 28.95 \\
\hline doublethreshold & 67.28 & 0.01 & -8.74 & -15.78 & -19.48 \\
\hline triple threshold & 5.16 & 0.05 & 8.05 & 3.87 & 2.04 \\
\hline
\end{tabular}

According to Table 2, the significance coefficients of single and double thresholds in the threshold effect have passed the critical value test at $1 \%$ level, and the $\mathrm{P}$ values of the test values are all less than 0.05. Based on the empirical needs of this paper, this paper focuses on the empirical test of the double threshold effect of environmental regulation on the efficiency of logistics industry. First, build the likelihood ratio function between variables as follows: $L R(\tau)=\left(\mathrm{S}_{1}(\tau)-\mathrm{S}_{1}(\hat{\tau})\right) / \hat{\sigma}^{2}$ According to the distribution formula of non-standard $L R$ statistics provided by Hansen (1999)[6], it can be inferred that $L R(\tau) \leq c(\alpha)(c(\alpha)=-2 \ln (1-\sqrt{1-\alpha}))$, in the double threshold can not reject the original hypothesis. The double threshold test results of the model at $95 \%$ confidence interval are shown in Table 3.

Table3. Results of threshold screening and double threshold estimation

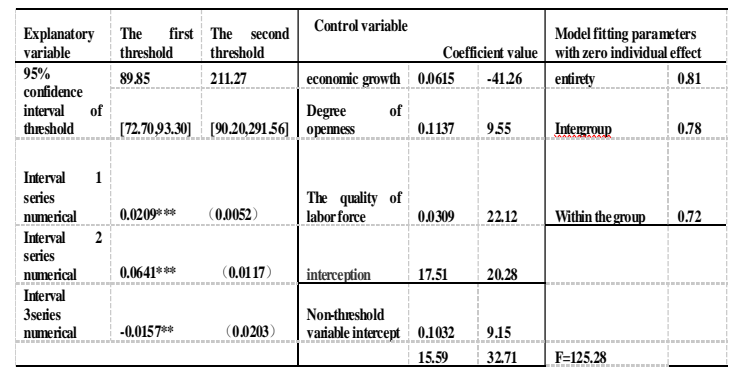

Table 3 shows that:

- The estimated values of the double threshold of the model at $95 \%$ confidence interval are 89.85 and 211.27 respectively. It can be seen that the threshold variables of environmental regulation affecting the green total factor productivity of logistics industry can be divided into three stages. low-level stage $(Y \leq 89.85)$, medium-level stage $(89.85<Y \leq 211.27)$ and high-level stage $(Y>211.27)$ of environmental regulation.

- The estimated results of the coefficient of control variables are consistent with the calculations of scholars such as Wang Qinmei (2013), Wang Zhaomi (2015) and Liao Min (2015). Economic growth, opening to the outside world and the comprehensive quality of the labor force all have positive effects on the improvement of the efficiency of the logistics industry, among which the degree of opening to the outside world is the most significant, and the improvement effect of the comprehensive quality of the labor force is limited. 
- Environmental regulation has a double threshold effect on the green total factor productivity of the logistics industry: when the total investment in environmental pollution control is at a low level, every $1 \%$ increase in environmental regulation increases the green total factor productivity of the logistics industry by $2.09 \%$; when the total investment in environmental pollution control is in the middle stage, environmental regulation increases the green total factor productivity of the logistics industry by $6.41 \%$. When the total investment in environmental pollution control is at a high level, every $1 \%$ increase in environmental regulation will reduce the green total factor productivity of the logistics industry by $1.57 \%$.

- The explanation of the non-linear effect of environmental regulation on green total factor productivity of logistics industry is that when the total investment in environmental pollution control is at a low level, environmental regulation gives full play to the innovation compensation effect in the efficiency of logistics industry by encouraging the application of new energy technologies in the industry, the optimization of transport routes and tools, and the improvement of transport efficiency. When the total investment in environmental pollution control is in the middle stage, enterprises are further encouraged by environmental regulation in logistics activities, and at the same time, they should accept certain government supervision of energy saving and emission reduction. Incentive and punishment jointly promote the optimization of logistics management system within the industry, forcing enterprises to continuously improve logistics efficiency. When the total investment of environmental pollution control is at a high level, environmental regulation has a large pollution control cost for the normal operation of the industry and enterprises, and pollution control increases the production cost of the enterprise. in the case of constant output, pollution control requires a large amount of capital invested by enterprises, which leads to the decline of the efficiency of the logistics industry.

\section{Conclusion and suggestion}

Based on the input-output panel data of logistics industry in 30 provinces and regions in China from 2005 to 2017, this paper uses nonparametric DEA model to evaluate the green total factor productivity of logistics industry, and further constructs a panel threshold model to empirically test the double threshold effect of environmental regulation on green total factor productivity of logistics industry. It is found that environmental regulation has a double threshold effect on green total factor productivity of logistics industry, and the estimated threshold values are 89.85 and 211.27 respectively. When environmental regulation is lower than 89.85 , environmental regulation has a positive improvement effect of $2.09 \%$ on green total factor productivity of logistics industry. the reason is that environmental regulation gives full play to the innovation compensation effect in the green total factor productivity of logistics industry by encouraging the application of new energy technologies. When environmental regulation is in the middle stage from 89.85 to 211.27 , environmental regulation has a positive improvement effect on green total factor productivity of logistics industry by $6.41 \%$. The reason is that environmental regulation incentives and government energy saving and emission reduction supervision promote the optimization of logistics management system within the industry and force enterprises to improve logistics efficiency. When the environmental regulation is higher than 211.27, the environmental regulation has a negative inhibitory effect on the green total factor productivity of the logistics industry. The reason is that the pollution control cost caused by the environmental regulation increases the production cost of the enterprise. When the output is constant, the enterprise invests more money, which leads to the decline of efficiency.

Based on the double threshold effect of environmental regulation in the green total factor productivity of the logistics industry, this paper puts forward the following suggestions: on the one hand, the green transformation of the logistics industry requires the government to encourage and intervene through the tools of environmental regulation. Therefore, it is necessary to bring the construction of ecological civilization into the performance evaluation of local governments. The government uses performance assessment as the baton to urge local officials to establish an effective environmental regulation system and force local governments to transform their governance, so as to avoid an extensive economic development model of changing resources and environment for growth. On the other hand, based on the fact that high-level environmental regulation has an obvious inhibitory effect on the green total factor productivity of the logistics industry, the government cannot adopt an across-the-board approach in restricting energy saving and emission reduction of the logistics industry through mandatory environmental regulation tools. To avoid irreversible production damage to enterprises by administrative orders, it should be based on the goals of local government economic development and resource and environmental protection. Government departments systematically guide the green transformation and upgrading of the logistics industry.

\section{Reference}

1. Li Hong, Zou Qing. Research on Environmental Regulation, Resource Endowment and Urban Industrial Transformation--based on the comparative analysis of resource-based cities and non-resourcebased cities [J]. Economic Research, 2018. 53 (11): 182-198.

2. Liu Chengliang, Guan Mingming. Spatial evolution and influencing factors of China's logistics efficiency under low-carbon constraints [J]. Geoscience, 2017, 
37 (12): 1805-1814.

3. Bian Guoli. Research on Retail Technology Progress and its influencing factors based on Super-efficiency DEA [J]. Business Economics Research, 2018 (13): 26-29.

4. Liu key, painting. Research on the influence of China's Industrial structure Adjustment on lowcarbon Logistics efficiency--an empirical Analysis based on Super-efficiency DEA low-carbon Logistics efficiency Evaluation Model [J]. Price Theory and practice, 2017 (12): 130-133.

5. Wang Xiaoli. Research on the threshold effect relationship between Social Security Expenditure and Regional Economic Development difference [J]. Business Economics Research, 2017 (10): 114, 116.

6. Zhang Yong, Peng Lijie, Mo Jiahao. The Measurement of China's Financial pressure and its Macroeconomic nonlinear effects $[\mathrm{J}]$. Statistical Research, 2017, 34 (01): 67-79. 